\title{
Numerical Simulation of Oil Jet Lubrication for High Speed Gears
}

\author{
Tommaso Fondelli, ${ }^{1}$ Antonio Andreini, ${ }^{1}$ Riccardo Da Soghe, ${ }^{2}$ \\ Bruno Facchini, ${ }^{1}$ and Lorenzo Cipolla ${ }^{3}$ \\ ${ }^{1}$ Department of Industrial Engineering, University of Florence, Via Santa Marta 3, 50139 Florence, Italy \\ ${ }^{2}$ Ergon Research srl, Via Panciatichi 92, 50127 Florence, Italy \\ ${ }^{3}$ GE Avio srl, Via Primo Maggio 56, 10040 Rivalta di Torino, Italy
}

Correspondence should be addressed to Tommaso Fondelli; tommaso.fondelli@htc.de.unifi.it

Received 31 July 2015; Accepted 17 November 2015

Academic Editor: Christopher J. Damaren

Copyright (C) 2015 Tommaso Fondelli et al. This is an open access article distributed under the Creative Commons Attribution License, which permits unrestricted use, distribution, and reproduction in any medium, provided the original work is properly cited.

\begin{abstract}
The Geared Turbofan technology is one of the most promising engine configurations to significantly reduce the specific fuel consumption. In this architecture, a power epicyclical gearbox is interposed between the fan and the low pressure spool. Thanks to the gearbox, fan and low pressure spool can turn at different speed, leading to higher engine bypass ratio. Therefore the gearbox efficiency becomes a key parameter for such technology. Further improvement of efficiency can be achieved developing a physical understanding of fluid dynamic losses within the transmission system. These losses are mainly related to viscous effects and they are directly connected to the lubrication method. In this work, the oil injection losses have been studied by means of CFD simulations. A numerical study of a single oil jet impinging on a single high speed gear has been carried out using the VOF method. The aim of this analysis is to evaluate the resistant torque due to the oil jet lubrication, correlating the torque data with the oil-gear interaction phases. URANS calculations have been performed using an adaptive meshing approach, as a way of significantly reducing the simulation costs. A global sensitivity analysis of adopted models has been carried out and a numerical setup has been defined.
\end{abstract}

\section{Introduction}

To reduce the environmental and climate impact from air traffic, the aeroengine industry and research community have been striving towards alternative engine configurations, with the aim of a significant reduction of specific fuel consumption. It is widely acknowledged that a SFC reduction can be achieved by increasing the engine bypass ratio. This is a key parameter to effectively improve propulsion efficiency, as well as reducing jet noise and engine emissions [1].

The Geared Turbofan (GTF) technology is one of the most promising engine configurations to increase bypass ratio. In this engine, a power epicyclical gearbox is interposed between the fan and the low pressure spool. Thanks to the power gearbox, fan and low pressure spool can turn at different speed. This brings some advantages: firstly, the fan speed can be reduced, leading to lower acoustic emissions; secondly, the speed of the low pressure spool can be sensibly increased, resulting in a more compact and efficient core engine.

The SFC is directly affected by the transmission efficiency of the gearbox and indirectly by the weight and the size of the cooling system. Therefore the gearbox efficiency becomes a key technology to achieve the benefits introduced by the GTF architecture. Although gearbox efficiency is higher than $99 \%$, power losses can be equally important in high power application like this. Further improvement of efficiency can be achieved developing a physical understanding of losses within the transmission system.

Sources of power losses in a gearbox can be classified into two groups [2]: load dependent and load independent (fluid dynamics losses). While there has been a large body of work dealing with load dependent power losses and suitable models for the prediction are already available, the fluid dynamics losses still need to be studied and properly modelled [3]. The load dependent power losses are primarily 
related to a mechanical power loss due to friction at the gear contact and between the rolling elements and the races of the bearings. The load independent power losses are primarily related to viscous effects and they are directly related to the lubrication method.

For very high speed (pitch velocity above $100 \mathrm{~m} / \mathrm{s}$ ) and high power gearboxes, typical of aeronautical applications, the lubrication is provided using nozzles to create small oil jets that feed oil into the meshing zone. It is essential that the gear teeth are properly lubricated and that enough oil gets into the tooth spaces for sufficient cooling, to ensure gearbox reliability. A good understanding of the oil jet behaviour inside the gearbox is therefore desirable, to minimize lubrication losses and reduce the oil volume involved.

Akin et al. [4] conducted several experimental tests about spur gear oil jet lubrication, varying gear and oil jet velocity. Pictures of oil jet lubrication were taken with a high speed motion camera, illuminating the lubricant with a xenon lamp. Their study reported how an optimal oil penetration depth was provided when the jet was not atomized, demonstrating how the trajectory of the small droplets is sensibly influenced by the aerodynamic field; no data was collected about the resisting torque due to the oil-gear interaction. Johnson et al. [5] presented an experimental study of the torque associated with a spiral bevel high speed gear in shrouded configuration, analysing the effect of various lubricant mass flow rates and shroud layouts. The measured data reported a linear increase in average torque with the oil mass flow rate and a good agreement between the average torque, derived by a simple calculation based on the oil's momentum variation, and the experimental torque was shown. Visualization through a transparent shroud showed that the oil was trapped under the shroud, leading to oil recirculation losses. This study highlighted how the resistant torque in a shrouded gear can be considered as the sum of three main loss terms: single-phase air windage, oil acceleration, and oil recirculation.

It should be noted that the experimental visualization of this kind of multiphase flow is difficult due to the high speeds of the gears; thus, computational fluid dynamics (CFD) simulations can provide a more in-depth understanding of the oil-gear interaction phenomena. Arisawa et al. [6] carried out an experimental and numerical study of the windage and oil churning losses within a prototype bevel gearbox. Lubrication oil was supplied to the gear meshing zone using many jet nozzles. The power fluid dynamics losses were derived by evaluating the difference between the oil discharge and supply temperature. The Volume of Fluid (VOF) and porous body methods were applied to model the two-phase flow and the gear meshing, respectively. A good agreement between CFD results, in terms of average power losses, and experiments was found. The global power losses were evaluated, while no data were reported about the contribution of the individual loss sources to the total loss.

The aim of the present work is to study the oil injection losses by means of CFD simulations. In order to reach a deeper knowledge of this loss, a comprehensive numerical study of a single oil jet impinging radially on a single spur gear has been carried out using the VOF method. The main objective of this work is to predict the resistant torque due to a high speed spur gear subject to oil jet lubrication, while the oil recirculation losses are not considered. Full unsteady simulations with moving meshes were carried out. The main challenges regarding this analysis are large threedimensional domain that leads to high computational cost, two-phase transient simulation, high speed free surface flow, and stationary and rotating domains. The VOF method, described by Hirt and Nichols [7], represents one of the most suitable methods to simulate oil jet impact on the moving gear teeth. This allows one to efficiently track the evolution of the oil surface within the calculation domain, capturing the air-oil interface, as well as the droplets and ligaments formation produced by jet's breakup. However this method requires a very fine mesh in the liquid region, leading to very high computational costs if a strategy for local grid refinement is not adopted. The solution adaptive mesh feature implemented in the commercial code ANSYS Fluent [8] has been used. This method provides several automatic criteria to refine and/or coarsen the grid based on geometric and numerical solution data. Hybrid adaptation functions have been created to confine the adaptation to specific domain regions. In order to carry out a global sensitivity analysis of grid adaptation strategy and model parameters, a simplified geometry has been defined. The resulting numerical setup has been adopted for the simulation of a reference geometry.

\section{Geometry and Operating Conditions}

2.1. Reference Geometry. The aim of this work is to study the forces exchanged between a high speed spur gear and the lubricating jet. To reach this goal, a representative geometry was defined (Figure 1). It consists of a spur gear confined within a symmetrical casing. The entire $360^{\circ}$ geometry is modelled.

The gear rotates at typical velocities of a high speed transmission. The lubricating jet is introduced by a cylindrical duct set up on the casing surface. The oil is directed towards the rotor axis, impinging on the gear face center. No outlet has been defined because as only few tooth passages were simulated, the lubricant volume injected is negligible with respect to the volume of air in the system.

The geometrical dimensions are summarized in Table 1. The defined gaps between transmission and casing are chosen in order to minimize domain volume, maintaining enough space in the radial direction to track the oil breakup during impact.

2.2. Theoretical Model. The expected average resistance torque produced by the oil jet lubrication can be estimated calculating the oil momentum variation during the interaction with the tooth. With reference to Figure 2, assuming that gear accelerates the oil up to the pitch line velocity, the resistant torque, as function of the oil injection angle, can be calculated as reported in

$$
\begin{aligned}
& F(\alpha)=\dot{m}_{j} \Delta U_{t}=\dot{m}_{j}\left(U_{p}-U_{j} \sin \alpha\right), \\
& T(\alpha)=\frac{P}{\omega}=\frac{U_{p} F}{\omega}=\frac{\dot{m}_{j}\left(U_{p}-U_{j} \sin \alpha\right)}{\omega} .
\end{aligned}
$$




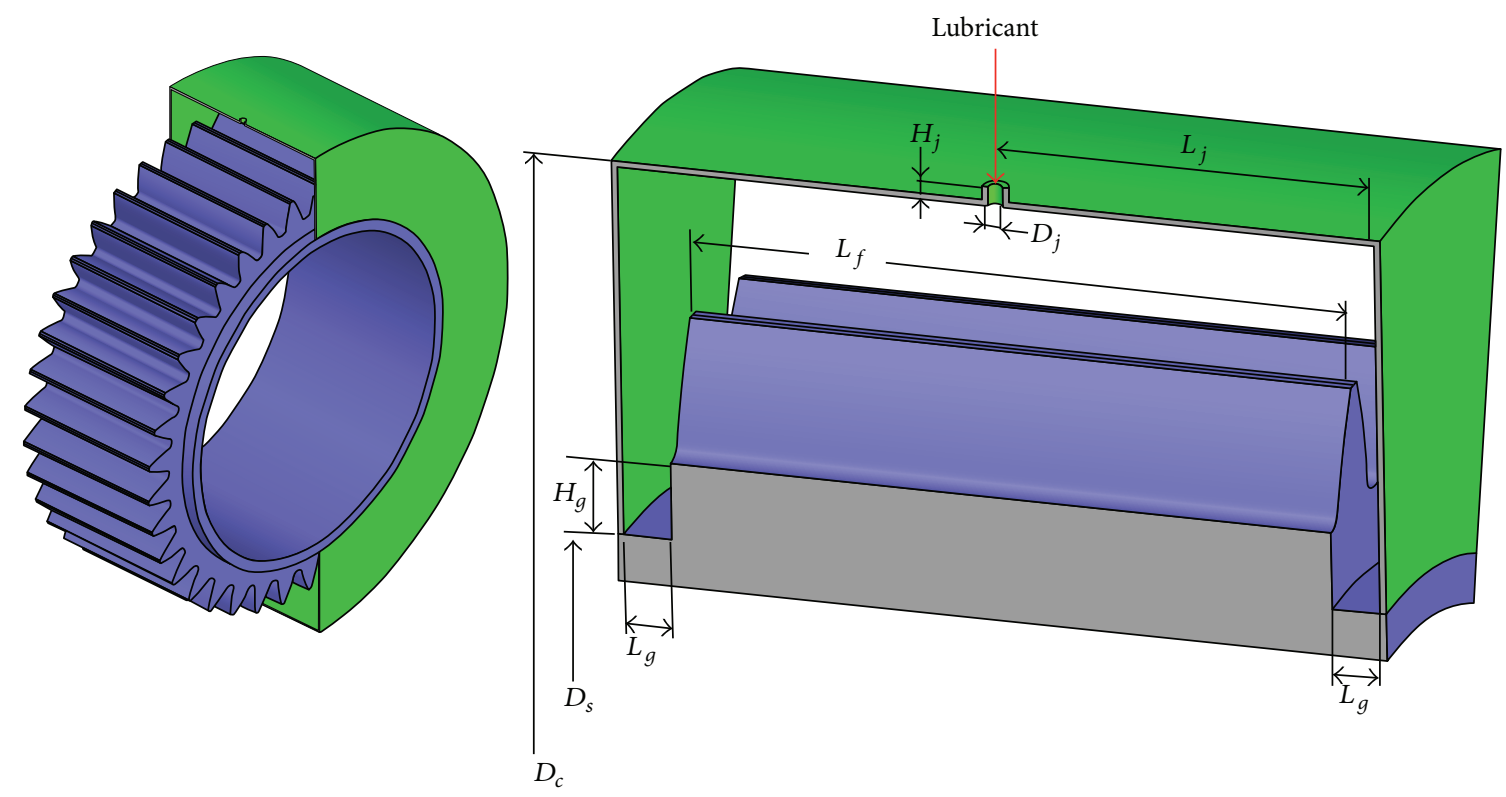

FIGURE 1: Sketch of reference geometry.

TABLE 1: Dimensionless geometrical parameters.

\begin{tabular}{lccccccc}
\hline$D_{p} / D_{j}$ & $D_{c} / D_{j}$ & $D_{s} / D_{j}$ & $L_{f} / D_{j}$ & $L_{g} / D_{j}$ & $H_{g} / D_{j}$ & $H_{j} / D_{j}$ & $Z$ \\
\hline 126.7 & 158.3 & 105 & 45.8 & 3.3 & 6.7 & 1 & 38 \\
\hline
\end{tabular}

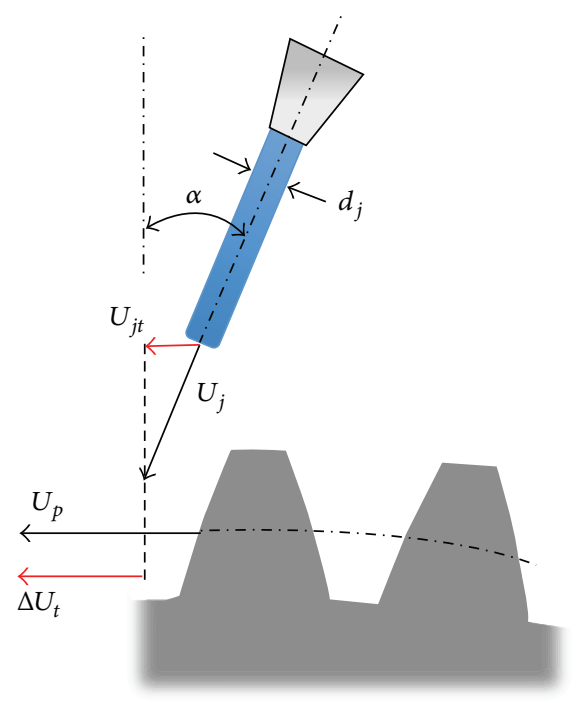

FIGURE 2: Sketch of 0D-Model.

The simple model provides a resistant torque equal to $T_{0}$ when the oil injection angle is set to a zero value

$$
T(0)=T_{0}=\dot{m}_{j} \omega R_{p}^{2}
$$

All torque values reported in this work have been made dimensionless using $T_{0}(2)$.
2.3. Operating Conditions. The operating conditions used in the simulations are representative of aeroengine cruise conditions:

(i) subatmospheric pressure condition,

(ii) temperature that was matched with the typical operating value within gearbox systems,

(iii) the ratio between the pitch line and the oil jet velocities that was fixed to 4 .

The choice of such conditions takes effect on the oil jet behaviour. The lubricant has to cross a rotating air flow before to impact on the gear teeth. As it will be shown in Section 4.1, the airflow is characterized by a tangential velocity of the same order of the pitch line velocity $\left(U_{\text {air }} \approx 0.9 U_{p}\right)$.

To a first approximation, the problem can be treated as an injection of liquid into a high speed crossflow (see Figure 3). For such issue, a lot of empirical correlations have been developed by many researchers to predict the liquid column trajectory, breakup distance $x_{b}$, and height $y_{b}$, for various flow conditions $[9,10]$. The main parameter governing the phenomenon is the liquid to gas momentum ratio (3) while the crossflow Weber number, (4), is the parameter that controls the breakup regime [11]

$$
\begin{aligned}
q & =\frac{\rho_{j} U_{j}^{2}}{\rho_{\mathrm{air}} U_{\mathrm{air}}^{2}}, \\
\mathrm{We}_{\mathrm{cf}} & =\frac{\rho_{\mathrm{air}} d_{j} U_{\mathrm{air}}^{2}}{\sigma}, \\
\frac{y_{b}}{d_{j}} & =k q^{n} .
\end{aligned}
$$

The correlations for $y_{b}$ have a power law form as reported in (5), where $k$ and $n$ are constant values; therefore the jet 


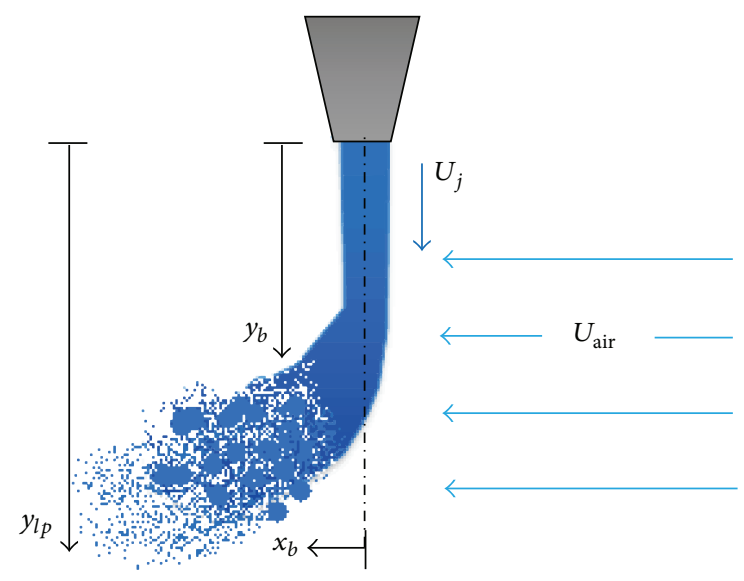

FIGURE 3: Sketch of liquid jet in the air crossflow.

penetration increases when $q$ goes up. Because of the small distance between the jet inlet and the gear surface (equal to 12.5 jet diameters) and the subatmospheric pressure condition that leads to a significant reduction of air density as well as the aerodynamic forces that act on the lubricant flow $\left(q=900\right.$ and $\left.\mathrm{We}_{\mathrm{cf}}=26\right)$, a notable oil breakup is not expected before the jet impact on the gear. On the contrary, at ambient pressure a significant oil jet breakup may take place, as a result of the air density increase.

As the oil jet hits the high speed gear teeth, a fast momentum transfer occurs. To identify the order of magnitude of the different phenomena involved, a dimensionless groups analysis has been carried out. The useful dimensionless groups for this multiphase system are listed below:

$$
\begin{aligned}
\operatorname{Re} & =\frac{\rho_{j} d_{j} U_{\mathrm{imp}}}{\mu_{j}}=3.2 \cdot 10^{4}, \\
\mathrm{We}_{j} & =\frac{\rho_{j} d_{j} U_{\mathrm{imp}}^{2}}{\sigma}=3.9 \cdot 10^{5}, \\
\mathrm{Fr} & =\frac{U_{\mathrm{imp}}^{2}}{g d_{j}}=9.0 \cdot 10^{5},
\end{aligned}
$$

where $U_{\text {imp }}$ is the oil jet impact velocity

$$
U_{\text {imp }}=\left(U_{j}^{2}+U_{p}^{2}\right)^{0.5}
$$

The liquid jet Weber number $\left(\mathrm{We}_{j}\right)$ represents the relative magnitude of the liquid inertia forces and surface tension forces, while the Froude number ( $\mathrm{Fr}$ ) characterizes the ratio of inertia and gravity forces. As shown by the dimensionless numbers, the phenomenon is driven by the inertia forces, whereas gravity and surface tension effects are negligible. After the impact, the lubricant can form a thin film on the tooth surface: at this time the characteristic length to be used in the dimensionless group is the film thickness, and the surface tension forces may not be negligible.

\section{CFD Modeling}

3.1. Computational Domains and Grids. In order to carry out a global sensitivity analysis of grid adaptation strategy and model parameters, a simplified geometry has been defined. Subsequently, the resulting numerical setup has been adopted for the reference geometry's simulation. Two simplifications have been used:

(i) symmetry boundary conditions,

(ii) simplified geometry.

The symmetry boundary condition has been used, exploiting the geometrical symmetry of the problem with respect to the oil jet axis. This condition leads to a considerable reduction of the computational cost, as only one half of the geometry has to be simulated. Preventing the flow from crossing the boundary, symmetry condition introduces an approximation in the URANS simulation, in fact the velocity components of the lubricant jet aligned with rotational axis are neglected. The impact on the resistant torque calculation due to this boundary condition will be evaluated in this work. The simplified geometry has been obtained by cutting the reference geometry with two radial planes passing through the gear teeth, as represented in Figure 4. Each plane is set 10 jet diameters away from the inlet axis, so that the gear face width is 20 times the oil jet diameter.

A sketch of the simplified computational domain is reported in Figure 5, while the computational domain of reference geometry is sketched in Figure 6. The boundary conditions at the inlet were assigned in terms of a velocityinlet boundary condition type:

(i) velocity components: $0,0,-U_{j}$,

(ii) oil volume fraction: 1 ,

(iii) turbulence equations: a low intensity and a length scale equal to $D_{j}$ that were assumed.

The reference pressure value was fixed at a point located on the symmetry plane highlighted in Figures 5 and 6. All the walls were treated as smooth with a no slip condition; casing and inlet duct walls were stationary, while the gear and shaft wall were rotating. The symmetry condition for the simplified and reference geometry was set at the surfaces indicated in Figures 5 and 6, respectively.

The computational domain has been subdivided into two domains: a rotating domain that encompasses the gear and the flow surrounding it and a stationary domain for the flow outside the gear region. The flow field within the rotor zone has been solved using the rotating reference frame equations, whereas the stationary zone uses the stationary frame equations. The sliding mesh model has been adopted in this paper to treat the stator-rotor interface. It is a mesh motion method wherein the rotor domain slides rigidly downwards along the stationary domain. Additionally, the rotor and stator zones are connected with each other through nonconformal interfaces; as the mesh motion is updated in time, the nonconformal interfaces are likewise updated to reflect the new positions of each zone. 

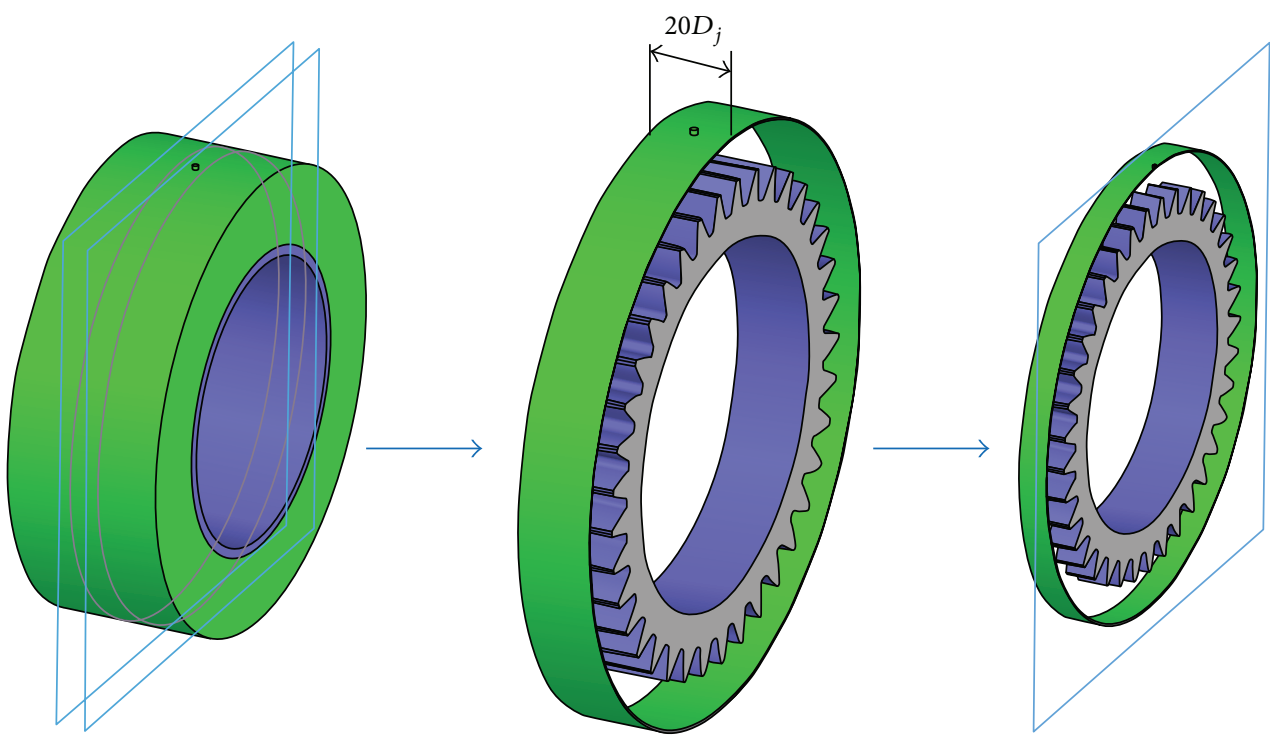

FIGURE 4: Simplified geometry definition.

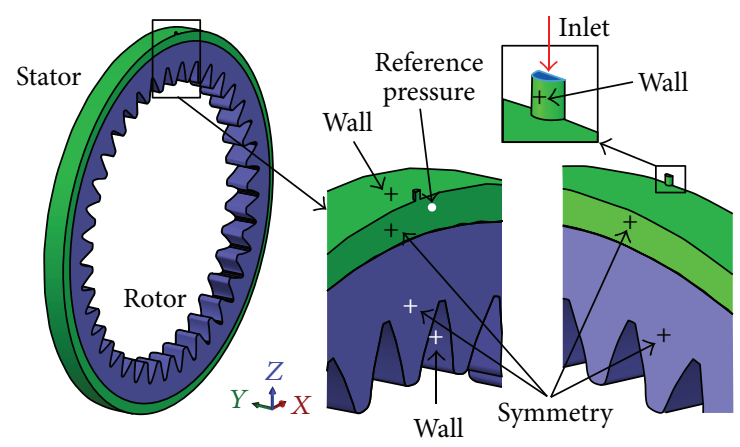

FIgURE 5: Simplified computational domain.

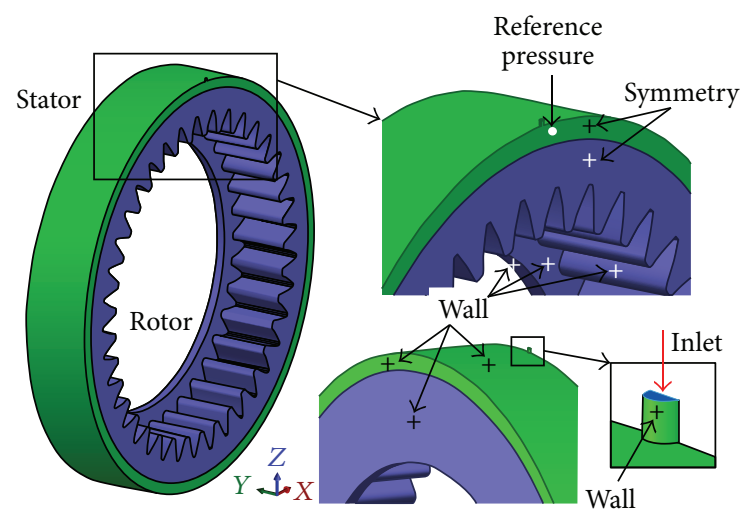

Figure 6: Computational domain of reference geometry.

The commercial code ANSYS ICEM-CFD has been used to generate the hexahedral meshes. The characteristics of the grids employed for the simulations are reported in Table 2 (see also Figure 7).
TABLE 2: Main features of the computational grids before VOF calculation.

\begin{tabular}{lccc}
\hline Geometry & Max size & Min size & Initial nodes \\
\hline Simplified & $D_{j} / 2$ & $D_{j} / 8$ & $1.06 \cdot 10^{6}$ \\
Reference & $D_{j} / 2$ & $D_{j} / 8$ & $2.79 \cdot 10^{6}$ \\
\hline
\end{tabular}

3.2. Grid Adaptation Method. The solution adaptive mesh feature implemented in ANSYS Fluent has been used with the aim to confine mesh refinements to specific regions, minimizing the simulation efforts. The initial meshes used in this work contain sufficient cells to represent the shape of the body and to capture the essential features of the aerodynamic flow field. The mesh regions to be adapted during VOF simulations are

(i) Liquid-Air Interface (LAI).

(ii) Near wall region (NWR).

The refinement of LAI region has been obtained by means of the gradient adaptation function, selecting the cells at the air-oil interface based on the normalized gradient of the volume fraction $(\nabla \phi)$. Maximum and minimum threshold values for $\nabla \phi$ were fixed before starting the simulation. In particular, the maximum value was set to 0.1 while the minimum was set to 0.001 . The cells, containing $\nabla \phi$ lower than the minimum threshold, are coarsened while cells having $\nabla \phi$ higher than the maximum threshold are refined. One of the purposes of this approach is to efficiently resolve the liquid surface minimizing numerical diffusion of the interface.

A hybrid adaptation function has been created to refine the NWR; combining the boundary adaptation and the isovalue adaptation functions, native functions of the code, the cells close to the gear tooth surface are refined only if 

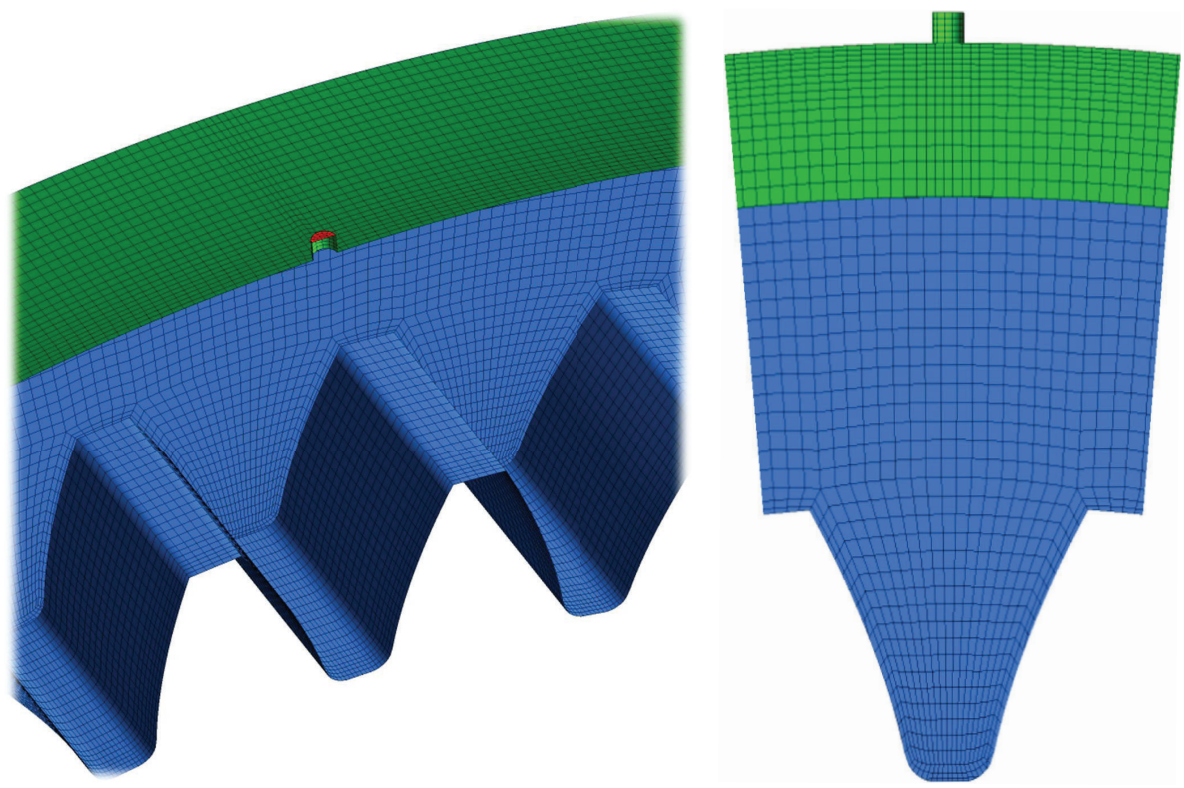

FIGURE 7: Computational grid of simplified geometry.
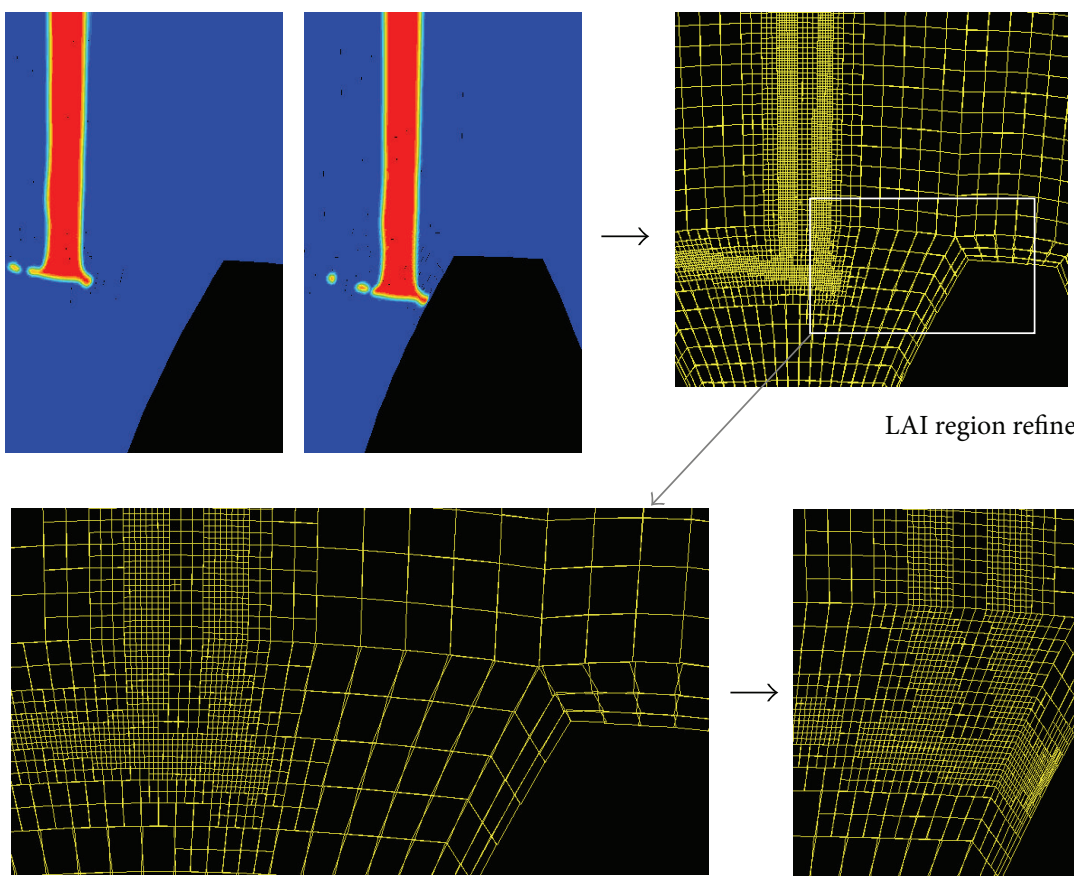

Before NWR refinement
LAI region refinement/coarsening
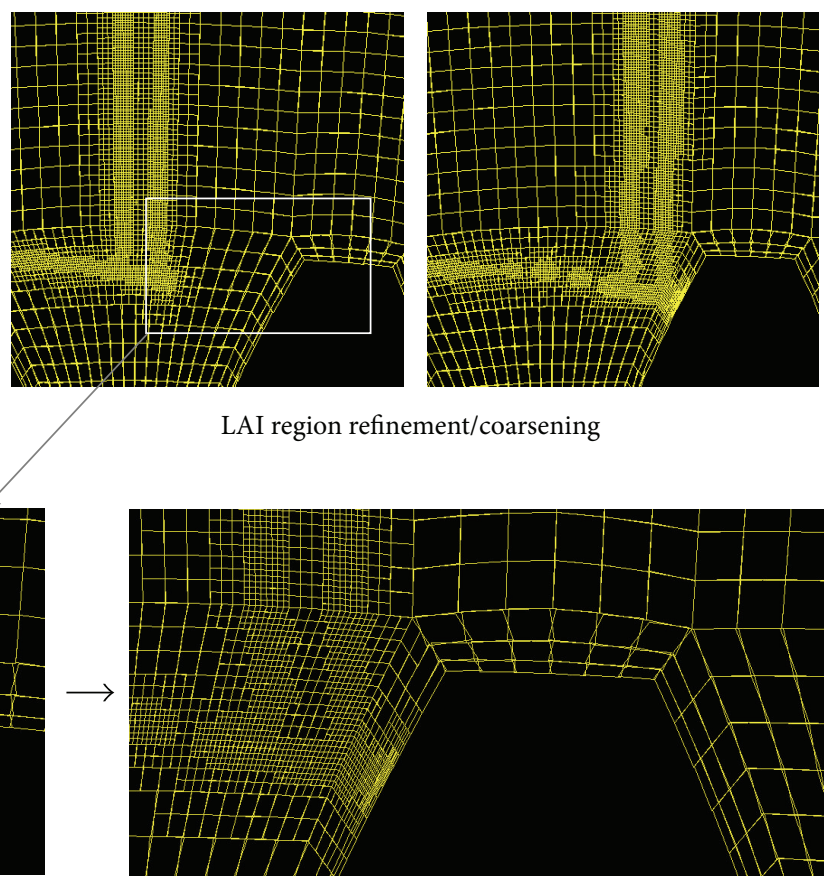

After NWR refinement

FIgURE 8: Mesh adaptation strategies.

the lubricant is present, in order to reproduce the strong velocity gradients and high shear stresses due to the liquidsolid interactions. A visualization of the adaptation strategies is reported in Figure 8.

The hanging node adaptation process [8] is used for the hexahedral grid used in the present work: the mesh is refined by splitting "parent" cell into 8 "child cells," adding a new point on each face of every parent cell. The level of refinement (LOR) is the parameter that fixes the maximum number of the hexahedron's splits. The mesh is coarsened by uniting the child cells to reclaim the previous parent cell. The grid cannot be coarsened any further than the original grid using the hanging node adaptation process. The adaptation processes are automatically and periodically executed during the unsteady calculation by means of an Execute Commands function. 
A sensitivity analysis of the results to the LOR parameter has been assessed for both strategies of refinement.

3.3. Numerical Setup. The commercial code ANSYS Fluent v14 has been used to solve the 3D unsteady RANS equations. A segregated solver with SIMPLEC scheme as velocitypressure coupling algorithm was selected, in conjunction with a first-order backward difference scheme for time discretization, and an explicit scheme for the VOF equation with implicit body forces. The flow system was treated as isothermal, considering air and oil as incompressible fluids (Mach number $<0.3$ ). The pressure field was discretized using PRESTO scheme. A second-order upwind scheme was used for the discretization of the velocity field. The compressive interface scheme was used for the volume fraction: this is a high resolution differencing scheme that produces an interface that is almost as sharp as the geometric reconstruction scheme [11]. The surface tension force was modelled using the continuum surface force (CSF) model proposed by Brackbill et al. [12]. Although more accurate approaches for the surface tension forces calculation exist, like the CLSVOF approach proposed by Sussman and Puckett [13], the VOF method with CSF model has been adopted because the twophase problem under consideration is not a surface tensiondominant flow $\left(\mathrm{We}_{j}=3.9 \cdot 10^{5}\right)$. An improvement of the surface tension forces calculation has been obtained acting on grid refinement.

Turbulence was modelled by means of $k-\varepsilon$ model, using scalable wall functions for near wall treatment to avoid the deterioration of standard wall functions under grid refinement below $y+<11$. For the convection terms firstorder discretization scheme was used.

The simulations have been carried out with fixed time step, by maintaining a global courant number lower than 1 . A typical resistant torque curve derived by the simulations is depicted in Figure 9: every torque peak is related to an oil jet impact on the gear tooth, and the first peak is the first one of the calculation. The torque data have been nondimensionalised by $T_{0}$ value, while the time has been nondimensionalised by 5 tooth passing intervals. Figure 9 shows how the calculation has reached a periodicity condition after a few impacts; therefore the simulations were stopped after five impacts. In order to assess the convergence quality of the solution, the scaled residuals were monitored at every time step. The scaled residuals reached a minimum of $5.5 \cdot 10^{-5}$ for every equation.

As regards computational efforts, the simulation of a simplified geometry with 4 levels of refinement for the NWR requires approximately 168 hours using 2 CPUs with Intel Xeon Processor E5-2630 with 8 cores or the equivalent of about 2700 CPU hours.

\section{Results}

4.1. Flow Field Initialization. Before starting the VOF simulations, the air flow distribution inside the system is computed. Unsteady single-phase calculations were run, imposing a wall condition at the lubricant inlet instead of the velocity-inlet

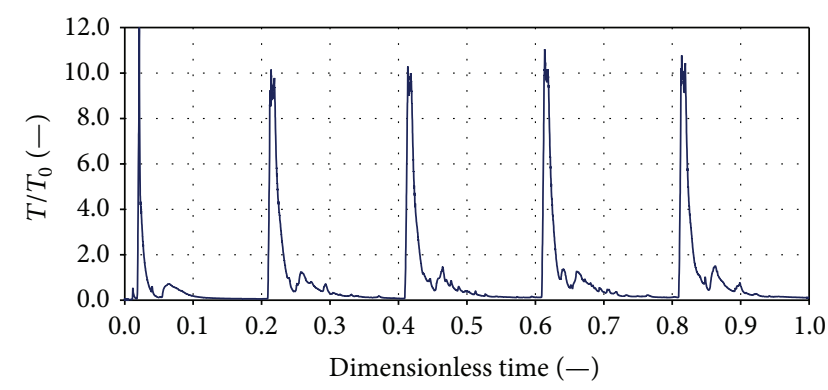

Figure 9: Dimensionless resistant torque curve resulting from calculation.

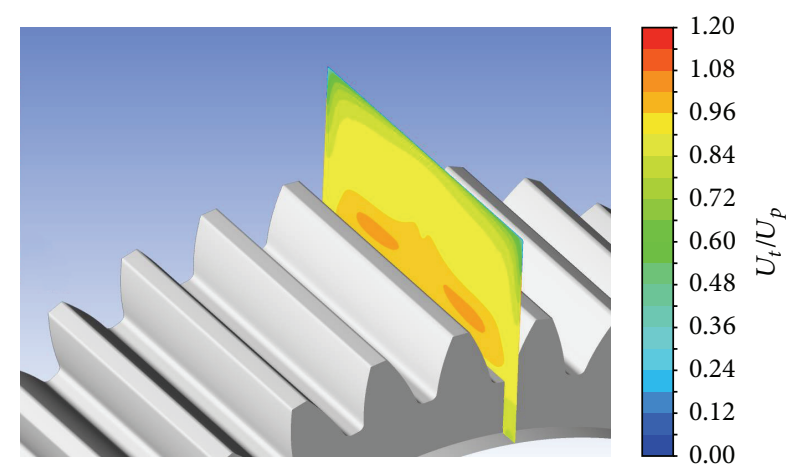

Figure 10: Contour plot of $U_{t} / U_{p}$ on the section plane for the reference geometry simulation.

condition. When the resisting torque reached an asymptotic value, the calculation was stopped.

In Figure 10 the contour plot of the absolute tangential velocity, made dimensionless by the pitch line velocity, is shown for the reference geometry simulation. How a rotating flow field occurs in the entire domain can be seen, and it is characterized by a tangential velocity of about $90 \%$ of the pitch line velocity in the region between the casing and the gear top land.

In high speed transmissions, the resistant torque due to windage effects becomes very intensive, as reported in the works of Dawson $[14,15]$. The calculation of windage losses is not the objective of this study, but it is calculated by VOF simulation and it is added to the resistant torque due to the oil jet lubrication. The subatmospheric pressure condition leads to a significant reduction of air density; as a consequence the windage torque decreases with respect to the lubrication torque; in fact windage losses are proportional to air density, as presented by Diab et al. [16]. The resultant windage torque will be subtracted from the torque calculated in the VOF simulation, in order to evaluate only the contribution due to the oil jet lubrication.

The windage torques resulting from the single-phase simulations of simplified and reference geometries are reported in Table 3. The values are nondimensionalised by the $T_{0}$ value and are relating to the entire gear of 38 teeth. 
TABLE 3: Dimensionless windage torques relating to single-phase simulations.

\begin{tabular}{lcc}
\hline Geometry & Simplified & Reference \\
\hline$T / T_{0}$ & 0.02 & 0.06 \\
\hline
\end{tabular}

4.2. Sensitivity Analysis. An extensive sensitivity study has been conducted, evaluating the effect of the computational parameters listed below:

(i) LOR parameter for LAI,

(ii) LOR parameter for NWR,

(iii) geometry simplification (symmetry condition).

A better description of the lubricant-gear interactions will be reported in the next section of this paper, while the main effects of modelling parameters on the resistant torque computations are now presented. The simulations that were carried out are reported in Table 4 . The average torque value, $T_{\text {ave }}$, is calculated resolving numerically (8), where the interval $[a, b]$ corresponds to the dimensionless time interval $[0.2,1]$. The first peak has not been considered in the average torque calculation

$$
T_{\mathrm{ave}}=\frac{1}{b-a} \int_{a}^{b} T(t) d t .
$$

Results have been compared in terms of the dimensionless average resistant torque, obtaining the bar chart represented in Figure 11.

The maximum and minimum values of $y+$ have been monitored at every time step: on the walls where the lubricant was present, the $y+$ values were kept within the range $[20 ; 170]$ in every simulation, while the mean value was kept within the range $[33 ; 52]$. A reduction of $25 \%$ in the upper limit of $y+$ and $37 \%$ in the mean values was achieved for the simulations where the NWR refinement was activated.

The level of refinement for the near wall region is the parameter that mainly affects the resistant torque. Run 1 has no near wall refinement and run 2 has LOR equal to 3 . In both of these cases there is very little variation in average torque compared to $T_{0}$. In fact the average torque for run 1 and run 2 is $99.5 \%$ of the $0 \mathrm{D}-$ Model value. With LOR fixed to 4 (run 3 ) the torque decreases by about $11.5 \%$ with respect to the $T_{0}$ value. No significant variation of resistant torque is achieved by further increasing the level of refinement; in fact the torque decreases only by $0.2 \%$ passing from LOR of 4 to LOR of 5. The explanation of these results can be achieved studying Figures 12, 13, and 14.

The results of run 1 and run 3 related to the second impact were compared in terms of torque trend (Figure 12) and velocity contour plot on the liquid surface (Figures 13 and 14). The points corresponding to the stages represented in the snapshots of Figures 13 and 14 are indicated in Figure 12 over the torque trends, in order to relate the main features of the impact time history to the physical evolution of the phenomenon.

From the data analysis, the liquid-gear interaction can be subdivided into four phases, summarized in Table 5 ,

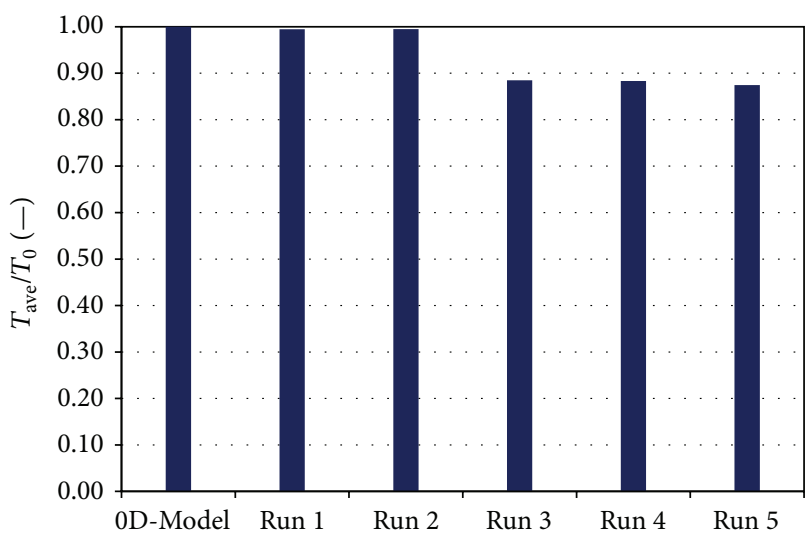

FIgURE 11: Dimensionless averaged torques.

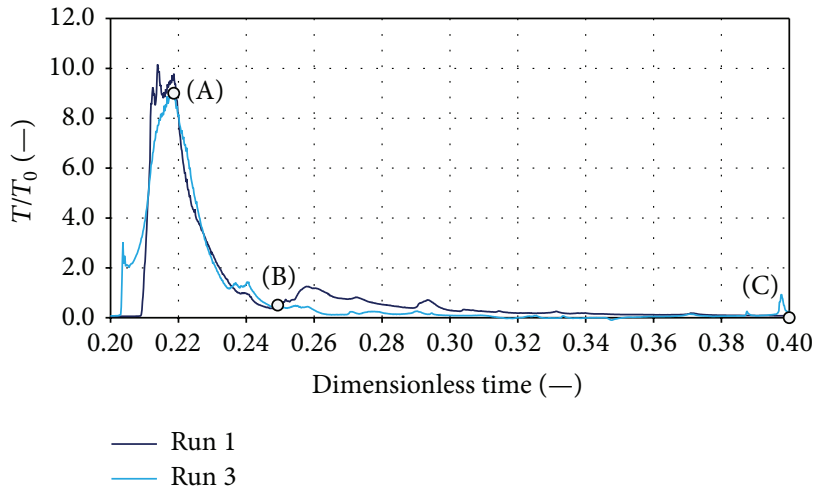

FIGURE 12: Dimensionless resistant torques during the second impact: run 1 versus run 3 .

corresponding to dimensionless time intervals: the oil jet hits the tooth face (phase a) and then passes over the front zone (phase b) and the rear zone of the gear top land (phase c) and finally the oil film, formed after the impact, moves on the tooth surface (phase d). The curves trend differs mainly during phases a, c, and d. To quantify such differences, the average torque related to each interaction phase has been calculated, as summarized in Table 6 .

The average torque for run 3 is $11.4 \%$ greater than run 1 value for the phase a and about $70 \%$ lower for phases $\mathrm{c}$ and $\mathrm{d}$; this last difference is the main factor leading to the overall average torque overestimation of run 1; in fact phases $\mathrm{c}$ and $\mathrm{d}$ represent together $75.4 \%$ of the overall oil-gear interaction time. The torque differences recorded during phases $\mathrm{c}$ and $\mathrm{d}$ have been investigated comparing the oil flow field for these periods. As shown in Figure 13(c), at the end of phase $d$ the oil covers the tooth crest in run 1 simulation, while no oil is observed in such region in run 3 (Figure 14(c)).

This behaviour can be explained by studying the contour plots of the volume fraction field on the symmetry plane, reported in Figure 15. For run 1 and run 2 the oil jet impinges on the tooth crest, forming an oil film that expands radially, exchanging momentum with the gear surface. When LOR is set to 4 , there are a larger number of computational cells within the boundary layer zone and then the strong velocity 
TABLE 4: Sensitivity analysis: test matrix.

\begin{tabular}{lccccc}
\hline Run & BC symmetry & LOR LAI & LOR NWR & Final nodes/initial nodes & $T_{\text {ave }} / T_{0}$ \\
\hline 1 & Yes & 3 & - & 3 & 2.6 \\
2.995 \\
2 & Yes & 3 & 4 & 4.2 & 0.995 \\
3 & Yes & 3 & 5 & 8.9 & 0.885 \\
4 & Yes & 3 & 4 & 7.9 & 0.883 \\
5 & No & 3 & & 0.874 \\
\hline
\end{tabular}

TABLE 5: Liquid-gear interaction phases.

\begin{tabular}{lcr}
\hline Phase & Description & Dimensionless time interval \\
\hline $\mathrm{a}$ & Oil jet hits the tooth face & $0.20-0.22$ \\
$\mathrm{~b}$ & Oil jet on the front zone of gear top land crest & $0.22-0.25$ \\
$\mathrm{c}$ & Oil jet on the rear zone of gear top land crest & $0.25-0.30$ \\
$\mathrm{~d}$ & Oil film motion on the tooth surface & $0.30-0.40$ \\
\hline
\end{tabular}

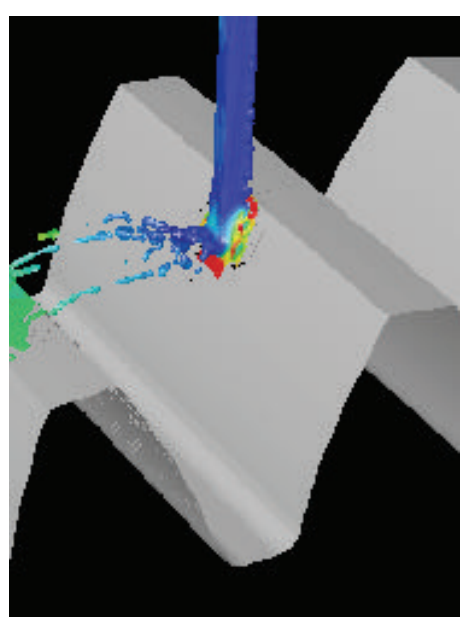

(a)

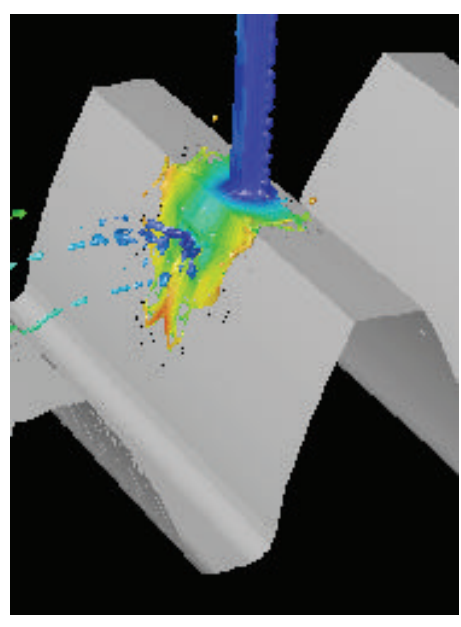

(b)

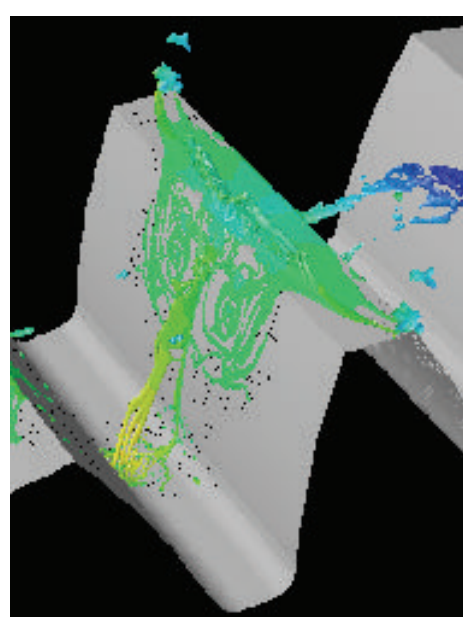

(c)

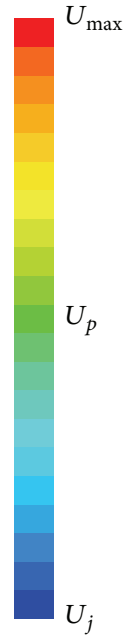

$U_{j}$

FIGURE 13: Run 1: contour plot of velocity on the liquid surface.

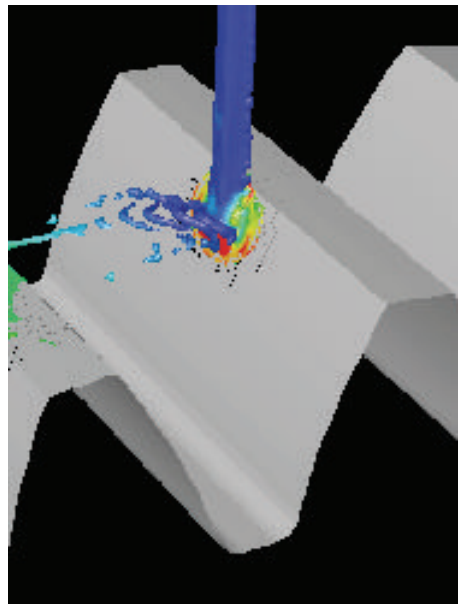

(a)

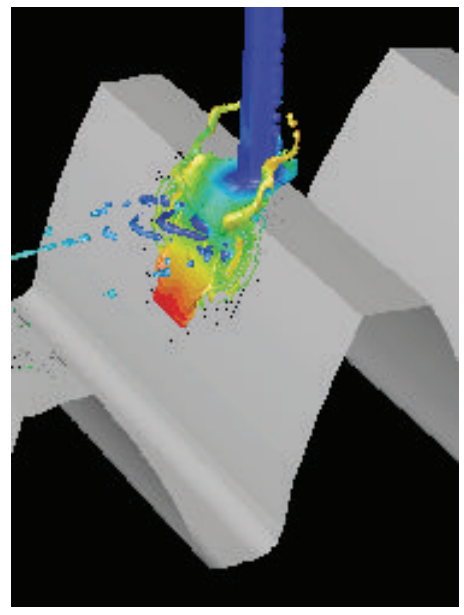

(b)

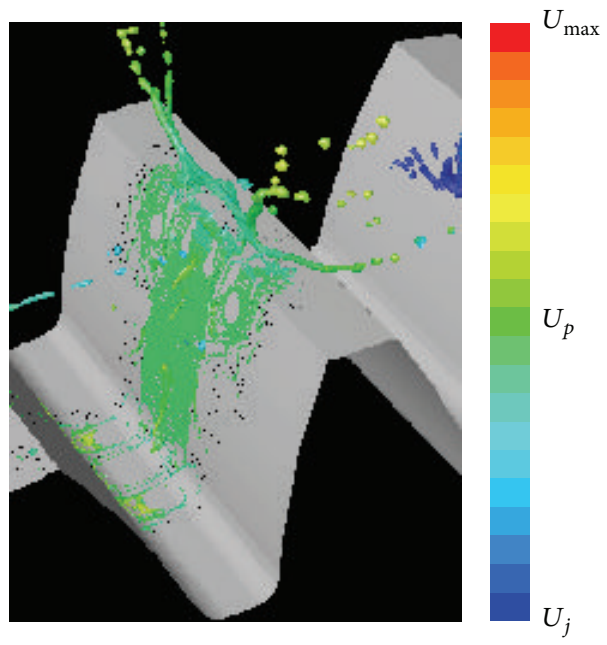

(c)

FIGURE 14: Run 3: contour plot of velocity on the liquid surface. 


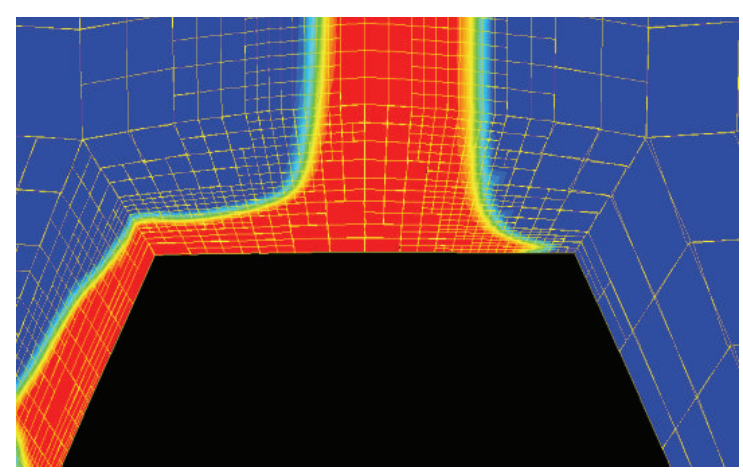

Run 1

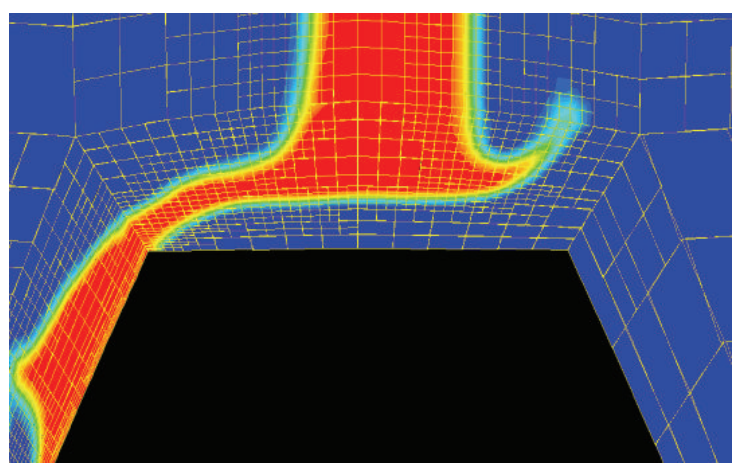

Run 3

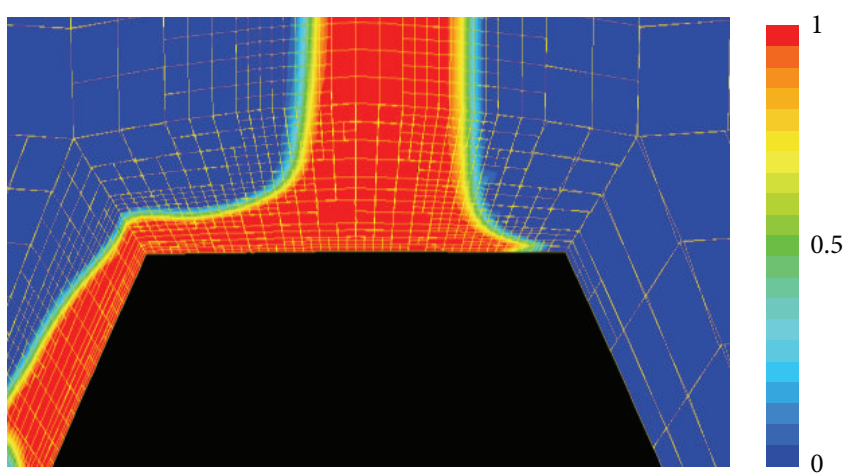

Run 2

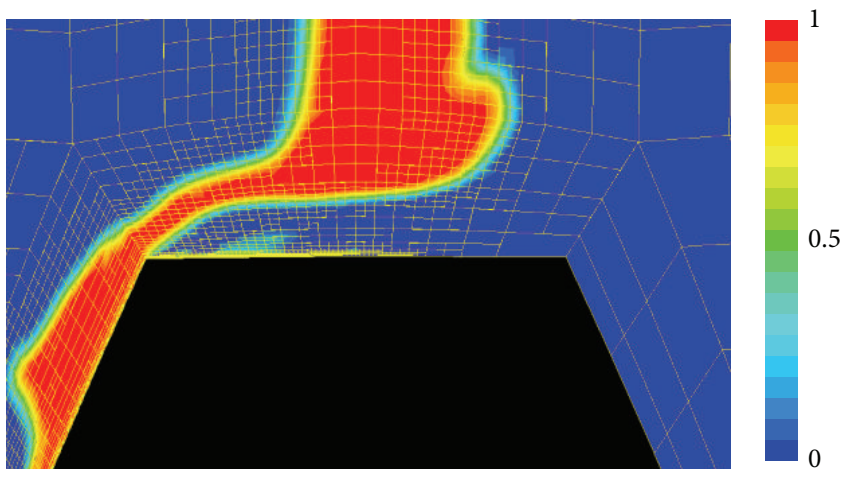

Run 4

FIGURE 15: Contour plot of oil volume fraction at the symmetry plane: runs 1, 2, 3, and 4.

TABLE 6: Average dimensionless torques related to the oil-gear interaction phases during the second impact: runs 1 and 3.

\begin{tabular}{lccccc}
\hline Phase & $\mathrm{a}$ & $\mathrm{b}$ & $\mathrm{c}$ & $\mathrm{d}$ & Overall \\
\hline$\Delta$ time $\%$ & 9.3 & 15.3 & 25.4 & 50.0 & 100 \\
\hline Run 1 & 3.85 & 2.53 & 0.67 & 0.14 & 0.985 \\
Run 3 & 4.29 & 2.71 & 0.20 & 0.04 & 0.884 \\
\hline
\end{tabular}

gradients, due to the liquid-solid interactions, are better reproduced. In this case, the oil jet does not impinge on the tooth crest but forms a suspended oil film. As the jet passes over the gear top land, the oil mass flow that reaches the jet base does not impinge on the gear surface but feeds the liquid film that breaks up into ligaments and small droplets. This amount of oil is not involved in the gear lubrication process and the total oil mass that exchanges momentum with the gear decreases, resulting in the resistant torque reduction. When the LOR parameter for near wall region is set to 5 (run 4), a similar suspended film is obtained.

To assess the effect of symmetry boundary condition on the torque calculation, in run 5 a new mesh was adopted. It was generated redoubling the grid used for the other runs with respect to the symmetry plane. The symmetry plane boundary condition does not significantly affect the results; in fact the average resistant torque for run 3 is $1.14 \%$ greater than run 4 value.
4.3. Reference Geometry Results. Two simulations of the reference geometry have been carried out, exploiting the numerical setup obtained by sensitivity analysis. The simulation parameters are reported in Table 7.

During the sensitivity analysis, the effects of the level of refinement for LAI on the resistant torque were not evaluated. This sensitivity has been assessed in the present section, comparing the average resistant torques arising from the simulations, as summarized in Table 7 . The average resistant torque derived by run $3 \mathrm{D}-2$ is only $3.8 \%$ lower than run $3 \mathrm{D}$ 1 value, while the mesh node number is about double. The main effect of the highest level of refinement for LAI regions is a greater breakup of oil ligaments after the impact with the gear. Below the results obtained by run 3D-2 are discussed.

A visualization of the resistant torque curve is depicted in Figure 16: how the curve reproduces the periodic nature of the jet lubrication can be seen. The instantaneous torque reaches a maximum value about 12 times above the mean value $T_{0}$.

A better description of the lubricant-gear interactions can be achieved focusing on the second impact: the resistant torque trend and the corresponding cumulative torque curve are depicted in Figures 17 and 18, respectively. In both graphs, some characteristic flow times are highlighted, in order to relate the torque history to the isosurface plots reported in Figure 19.

The oil jet hits the tooth flank (point 1): the momentum transfer occurs in a very short time, leading to the resistant 
TABLE 7: Modelling parameters adopted in the reference geometry simulations.

\begin{tabular}{lccccc}
\hline Run & BC symmetry & LOR LAI & LOR NWR & Final nodes/initial nodes & Averaged torque \\
\hline 3D-1 & Yes & 3 & 4 & 2.3 & 0.899 \\
3D-2 & Yes & 4 & 4 & 3.9 & 0.865 \\
\hline
\end{tabular}

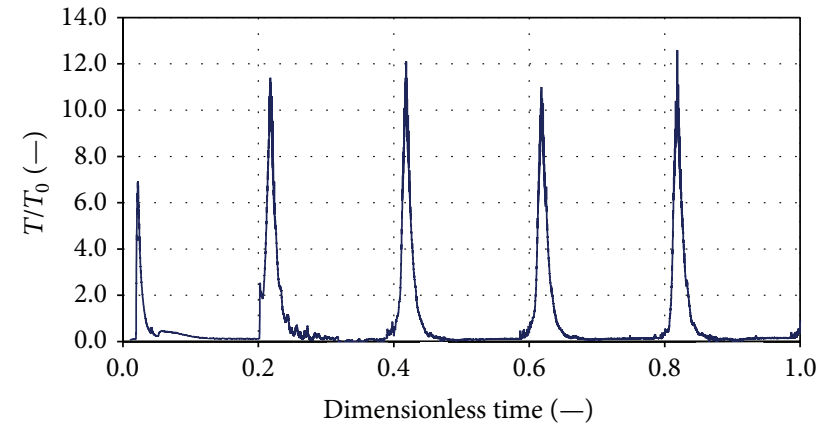

FIGURE 16: Dimensionless resistant torque curve for run 3D-2.

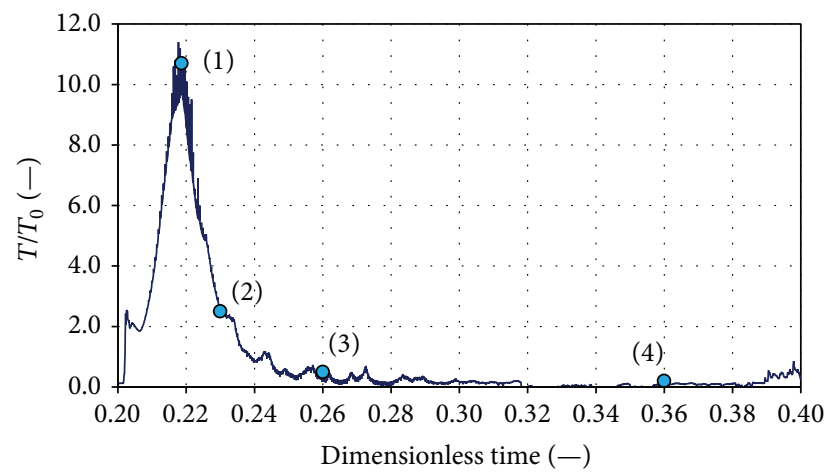

FIGURE 17: Second impact data related to run 3D-2: dimensionless resistant torque.

torque peak. At this time the tooth has transferred to the liquid thirty percent of the total momentum exchanged. On the tooth flank, the jet forms a thin oil film that gets down with high velocity toward the gear axis.

When the oil jet is passing over the gear top land, the lubricant does not impinge on the gear but forms a liquid film that flies over the tooth (Figures 19(b) and 19(c)). At this time, the lubricant that is reaching the jet base feeds the suspended film that breaks up into ligaments and small droplets. This amount of oil is not involved in the gear cooling process, and the total oil mass that exchanges momentum with the gear decreases, resulting in a reduction of average torque with respect to $0 \mathrm{D}$-Model value. The jet remains connected to the oil on the tooth flank by means of the film: the jet drags the oil ligament close to the tooth crest until the oil film does not break up, as visible in Figure 19(d). The detached oil ligament moves away from the gear tooth in the radial direction, spreading in the axial direction. When the oil jet is passing over the tooth crest (point 3 ) the gear has transmitted ninety percent of the total momentum.

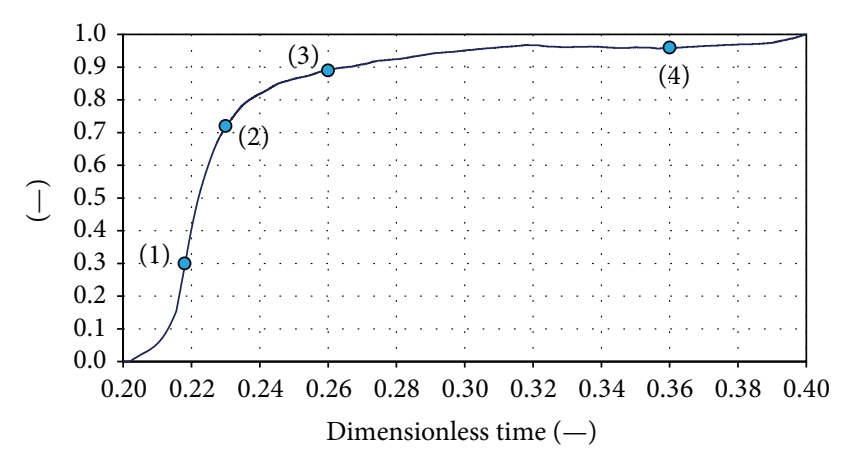

Figure 18: Second impact data related to run 3D-2: cumulative torque curve normalized.

In order to analyse the relative contribution of pressure and shear forces to the resistant torque calculation, the normalized cumulative torque curves, resulting from both forces, are reported in Figure 20. These data pieces are related to the second impact. How the shear force contribution is very low can be observed; in particular, it is at least two orders of magnitude lower than the pressure data. This result proves that the mechanism which mainly contributes to the resistant torque is the pressure distribution on the tooth flank resulting from the oil jet impact, while the shear forces contribution is negligible.

\section{Conclusions}

A comprehensive numerical study of a single oil jet impinging radially on a single high speed gear has been carried out using VOF method. The adapting mesh feature, implemented in the commercial code ANSYS Fluent, has been used, developing hybrid adaptation functions to confine the adaptation to specific domain regions.

A global sensitivity analysis of grid adaptation strategy and model parameters was carried out. The level of refinement adopted for the near wall region is the parameter that mainly affects the simulation results, while the effect of other computational parameters is less significant. Thus a robust numerical setup has been defined.

This study has allowed the evaluation of the resistant torque due to oil jet cooling, developing more in-depth understanding of the oil-gear interaction phenomena. In particular, a good agreement between the average torque derived by a simple calculation based on the oil's momentum variation and the computational torque has been revealed. CFD results showed how the oil jet does not impinge on the gear top land but forms a suspended oil film that breaks up into ligaments and small droplets. This amount of oil is not involved in the gear lubrication process and the total oil mass that exchanges momentum with the gear decreases, resulting 

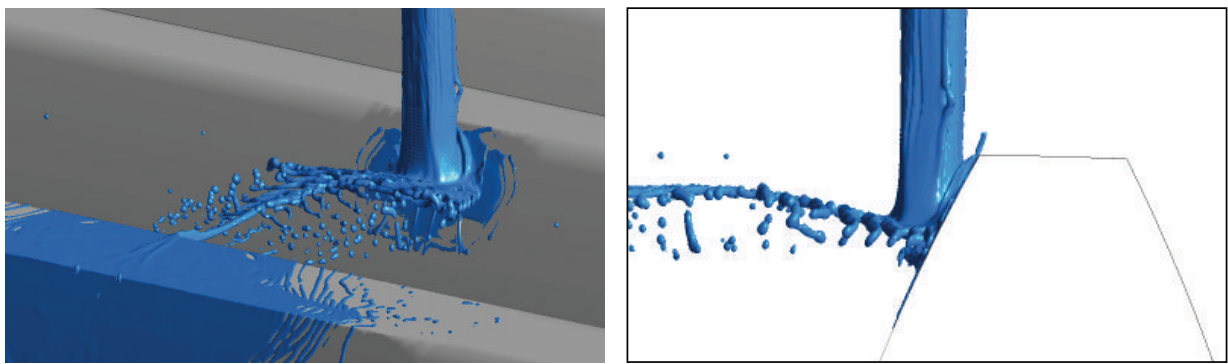

(a) Dimensionless time $=0.22$
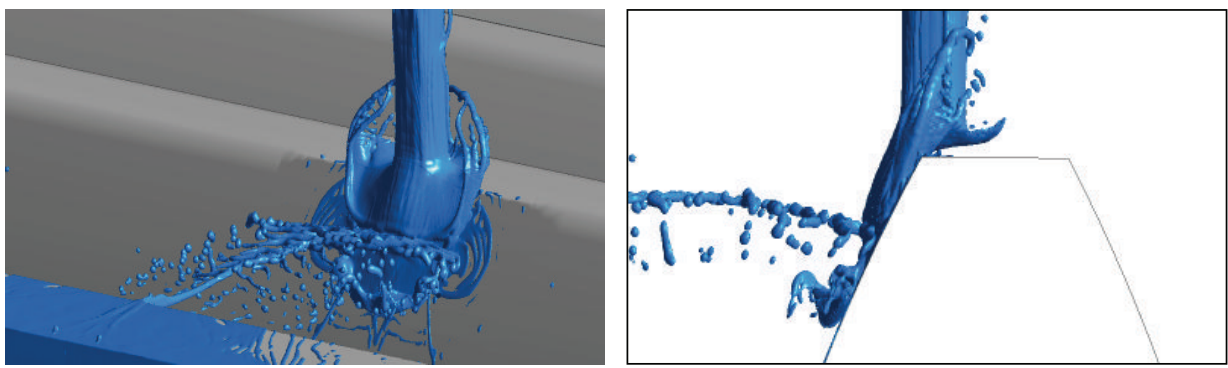

(b) Dimensionless time $=0.23$
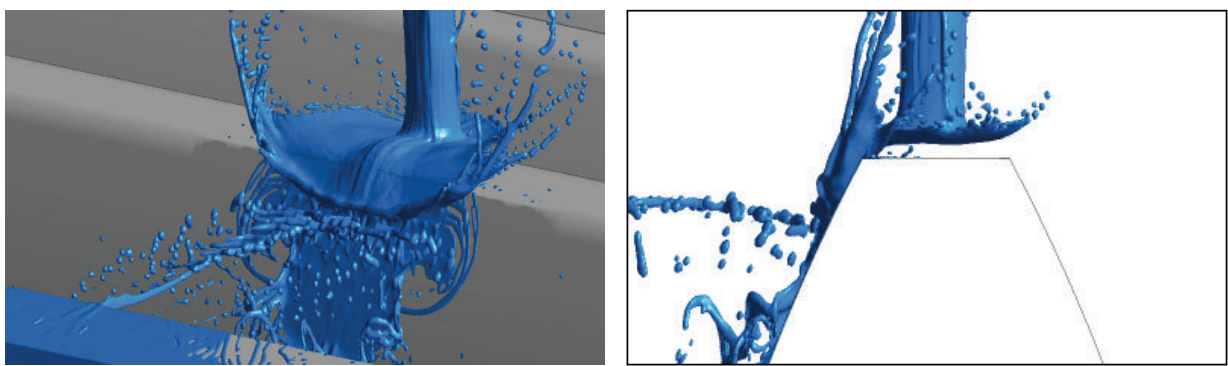

(c) Dimensionless time $=0.26$
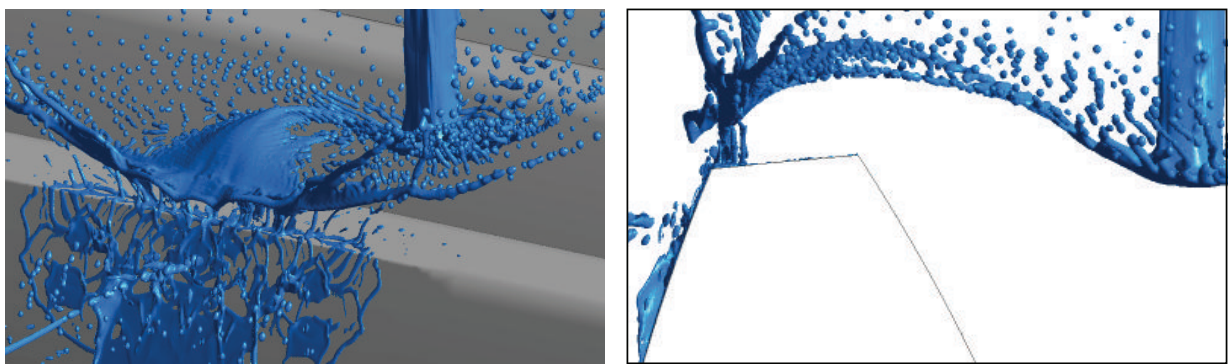

(d) Dimensionless time $=0.36$

FIGURE 19: Run 3D-2: isosurface of oil volume fraction $=0.1$

in a reduction of the average torque with respect to the $0 \mathrm{D}$ Model value.

Finally, it has been proved that the mechanism which mainly contributes to the resistant torque is the pressure distribution on the tooth flank resulting from the oil jet impact, while the shear forces contribution is negligible.

\section{Nomenclature}

$\alpha$ : Dimensionless oil jet injection angle

D: Diameter

$F$ : Force
Fr: Froude number

L: $\quad$ Length

$\omega$ : Angular velocity

$R: \quad$ Radius

Re: Reynold number

T: Torque

$U: \quad$ Velocity

$\mathrm{We}_{j}$ : Liquid jet Weber number

$\mathrm{We}_{\mathrm{cf}}$ : Crossflow Weber number

$x_{b}$ : Liquid column breakup distance

$y_{b}$ : Liquid column breakup height

$Z$ : $\quad$ Number of gear teeth. 


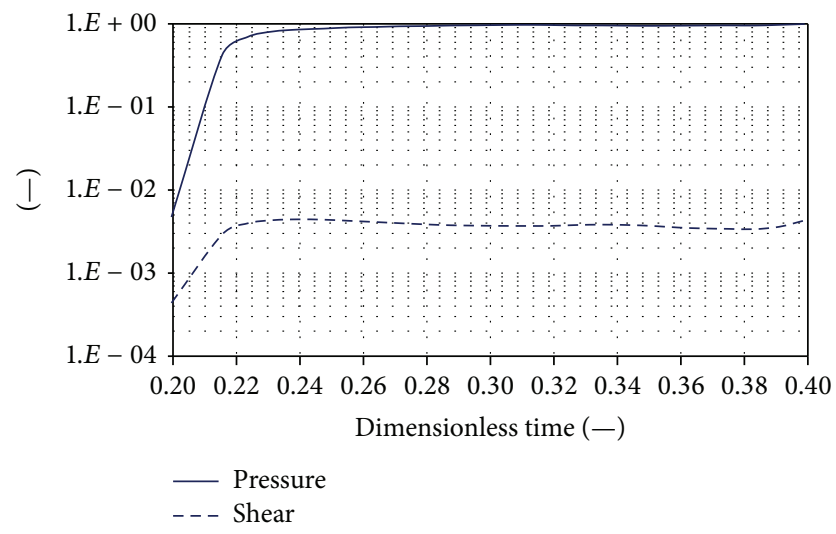

FIGURE 20: Second impact data related to run 3D-2: normalized cumulative torque curves resulting from pressure and shear forces.

$\begin{array}{ll}\text { Subscripts } \\ \text { ave: } & \text { Average property } \\ c: & \text { Casing property } \\ f: & \text { Tooth face } \\ g: & \text { Axial Gap } \\ \text { imp: } & \text { Impact } \\ p: & \text { Pitch property } \\ j: & \text { Jet property } \\ s: & \text { Shaft property } \\ t: & \text { Tangential value } \\ 0: & \text { Zero value. }\end{array}$

\section{Acronyms}

CFD: Computational fluid dynamics

LAI: $\quad$ Liquid-Air Interface

LOR: Level of refinement

NWR: Near wall region

URANS: Unsteady Reynolds Averaged Navier Stokes

VOF: Volume of Fluid.

\section{Conflict of Interests}

The authors declare that there is no conflict of interests regarding the publication of this paper.

\section{Acknowledgments}

The authors would like to thank GE Avio srl for the publication permission.

\section{References}

[1] S. Farokhi, Aircraft Propulsion, John Wiley \& Sons, 2014.

[2] S. Seetharaman and A. Kahraman, "Load-independent spin power losses of a spur gear pair: model formulation," Journal of Tribology, vol. 131, no. 2, Article ID 022201, 11 pages, 2009.

[3] C. N. Eastwick and G. Johnson, "Gear windage: a review," Journal of Mechanical Design, vol. 130, no. 3, Article ID 034001, 2008.
[4] L. S. Akin, D. P. Townsend, and J. J. Mross, "Study of lubricant jet flow phenomena in spur gears," Technical Memorandum TM X-71572, NASA, 1974.

[5] G. Johnson, B. Chandra, C. Foord, and K. Simmons, "Windage power losses from spiral bevel gears with varying oil flows and shroud configurations," Journal of Turbomachinery, vol. 131, no. 4, Article ID 041019, 2009.

[6] H. Arisawa, M. Nishimura, H. Imai, and T. Goi, "CFD simulation for reduction of oil churning loss and windage loss on aeroengine transmission gears," in Proceedings of the ASME Turbo Expo: Power for Land, Sea, and Air, vol. 1 of ASME Proceedings, pp. 63-72, ASME, Orlando, Fla, USA, June 2009.

[7] C. W. Hirt and B. D. Nichols, "Volume of fluid (VOF) method for the dynamics of free boundaries," Journal of Computational Physics, vol. 39, no. 1, pp. 201-225, 1981.

[8] Ansys Fluent, “Theory Guide," Release 14.0, 2013.

[9] P.-K. Wu, K. A. Kirkendall, R. P. Fulle, and A. S. Nejad, "Breakup processes of liquid jets in subsonic crossflows," Journal of Propulsion and Power, vol. 13, no. 1, pp. 64-73, 1997.

[10] P.-K. Wu, K. A. Kirkendall, R. P. Fuller, and A. S. Nejad, "Spray structures of liquid jets atomized in subsonic crossflows," Journal of Propulsion and Power, vol. 14, no. 2, pp. 173-182, 1998.

[11] J. Mazallon, Z. Dai, and G. M. Faeth, "Primary breakup of nonturbulent round liquid jets in gas crossflows," Automization and Sprays, vol. 9, no. 3, pp. 291-311, 1999.

[12] J. U. Brackbill, D. B. Kothe, and C. Zemach, "A continuum method for modeling surface tension," Journal of Computational Physics, vol. 100, no. 2, pp. 335-354, 1992.

[13] M. Sussman and E. G. Puckett, "A coupled level set and volumeof-fluid method for computing 3D and axisymmetric incompressible two-phase flows," Journal of Computational Physics, vol. 162, no. 2, pp. 301-337, 2000.

[14] P. H. Dawson, "Windage loss in larger high-speed gears," Proceedings of the Institution of Mechanical Engineers Part A: Journal of Power and Energy, vol. 198, no. 1, pp. 51-59, 1984.

[15] P. H. Dawson, "High-speed gear windage," GEC Review, vol. 4, no. 3, pp. 164-167, 1988.

[16] Y. Diab, F. Ville, P. Velex, and C. Changenet, "Windage losses in high speed gears-preliminary experimental and theoretical results," Journal of Mechanical Design, vol. 126, no. 5, pp. $903-$ 908, 2004. 

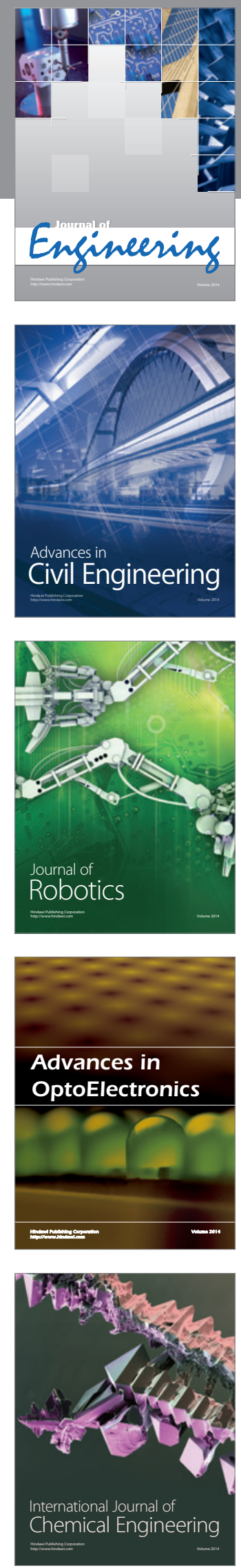

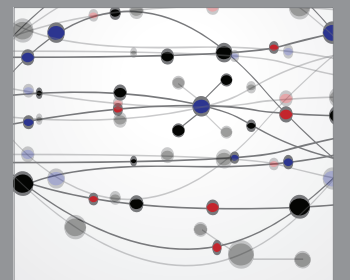

The Scientific World Journal
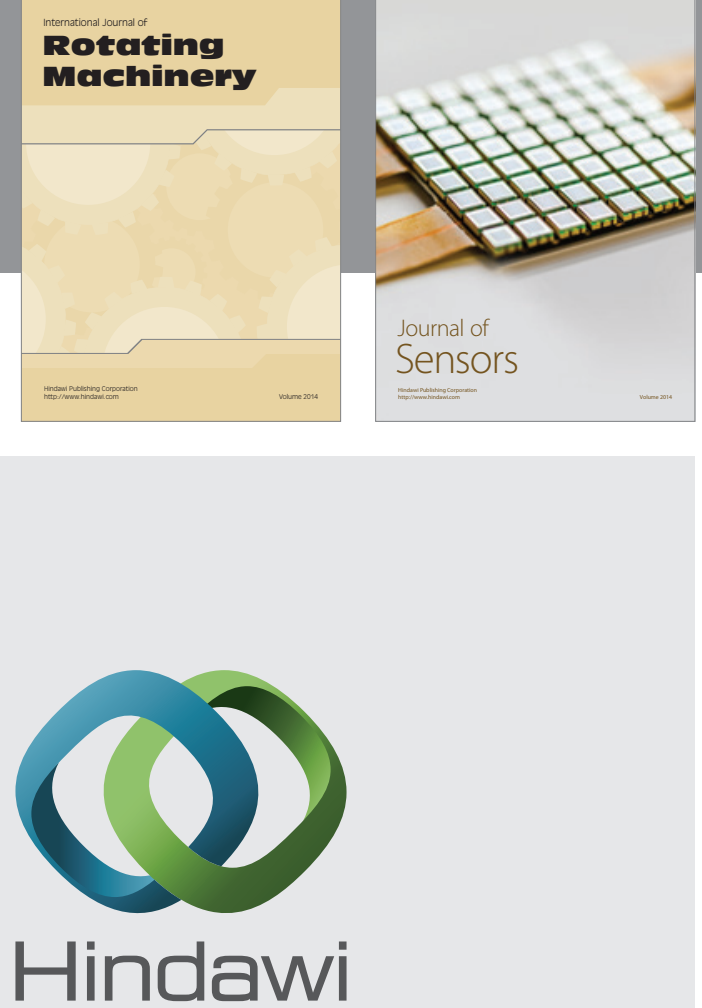

Submit your manuscripts at http://www.hindawi.com
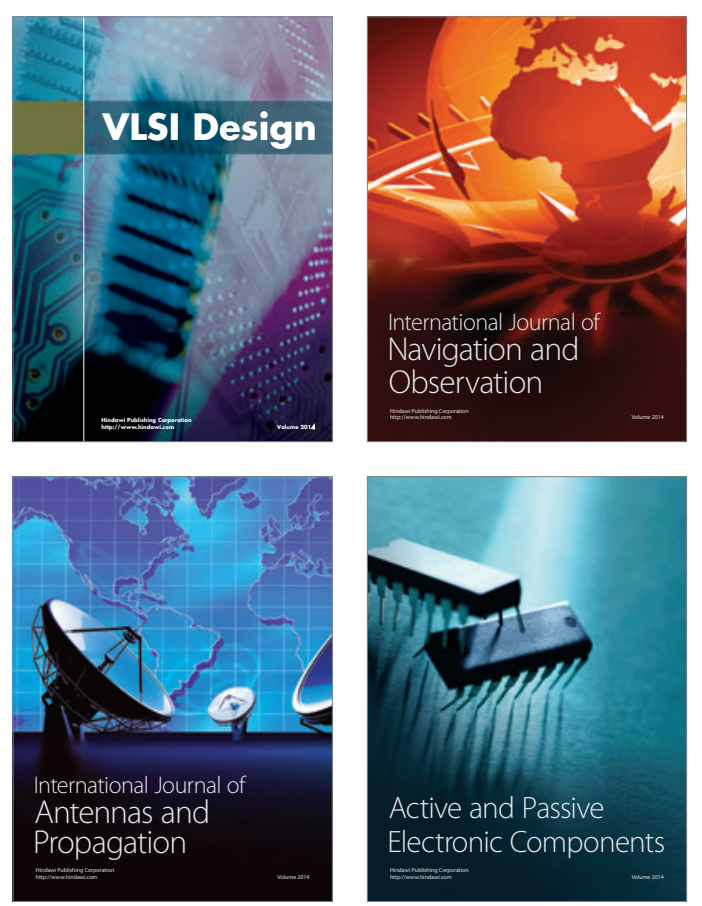
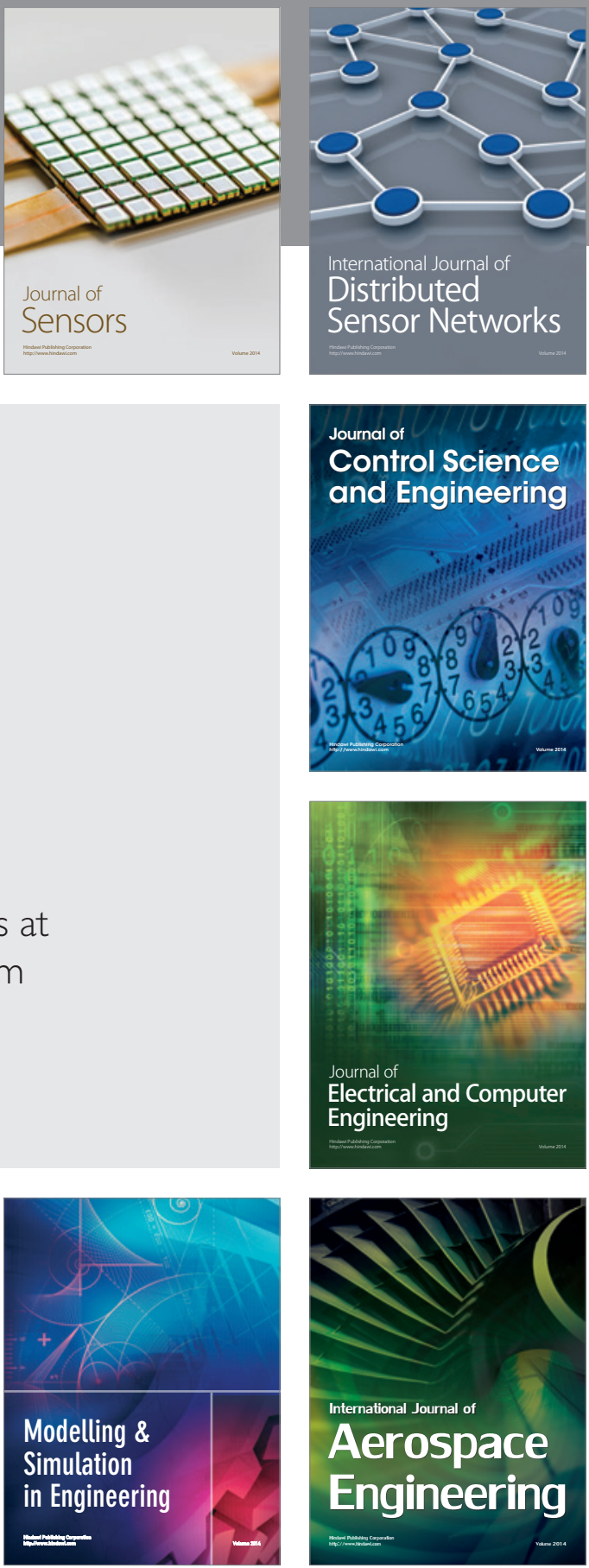

Journal of

Control Science

and Engineering
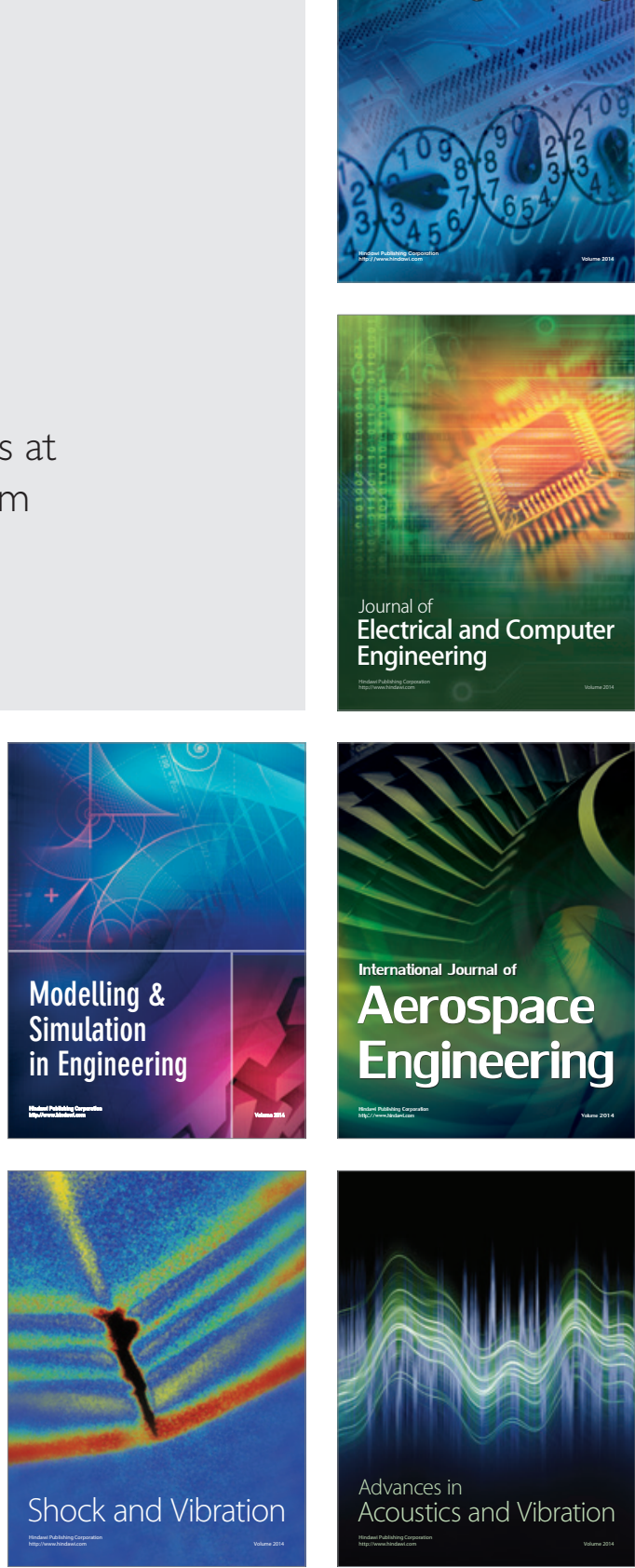